\title{
Lehrbuch der Massage
}

Von

\author{
San. $=$ Rat Dr. A. Müller \\ in M.=Gladbad.
}

Zroeite umgearbeitete und stark vermehrte Auflage

Erster Band:

Die funktionellen Erkrankungen des Berwegungsapparates und die Theorie der Massage

Mit 99 Abbildungen

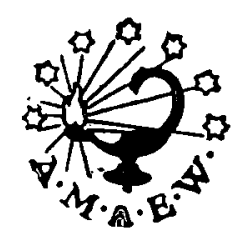

A. MARCUS \& E. WEBER'S VERLAG , BONN 1926 
Nachdruck verboten.

Alle Rechte, besonders das der Übersetzung in fremde Sprachen, behält sich der Verlag vor.

Copyripht by A. Marcus \& E. Weber's Verlag, Bonn 1926.

Otto Wigand'sche Buchdruckerel O.m. b. H., Leipzig. 